\title{
Bioluminescence of the poecilostomatoid copepod Oncaea conifera
}

\author{
Peter J. Herring ${ }^{1}$, M. I. Latz ${ }^{2}$, N. J. Bannister ${ }^{3}$, E. A. Widder ${ }^{4}$ \\ ${ }^{1}$ Institute of Oceanographic Sciences, Deacon Laboratory, Brook Road Wormley, Surrey GU8 5UB, United Kingdom \\ ${ }^{2}$ Marine Biology Research Division 0202, Scripps Institution of Oceanography, La Jolla, California 92093, USA \\ ${ }^{3}$ School of Biological Sciences, University of Birmingham, Edgbaston, Birmingham B15 2TT, United Kingdom \\ ${ }^{4}$ Harbor Branch Oceanographic Institution, 5600 Old Dixie Highway, Fort Pierce, Florida 34946, USA
}

\begin{abstract}
The small poecilostomatoid copepod Oncaea conifera Giesbrecht bears a large number of epidermal luminous glands, distributed primarily over the dorsal cephalosome and urosome. Bioluminescence is produced in the form of short ( 80 to $200 \mathrm{~ms}$ duration) flashes from within each gland and there is no visible secretory component. Nevertheless each gland opens to the exterior by a simple valved pore. Intact copepods can produce several hundred flashes before the luminescent system is exhausted. Individual flashes had a maximum measured flux of $7.5 \times 10^{10}$ quanta $\mathrm{s}^{-1}$, and the flash rate follows the stimulus frequency up to $30 \mathrm{~s}^{-1}$ Video observations show that individual glands flash repeatedly and the flash propagates along their length. The gland gross morphology is highly variable although each gland appears to be unicellular. The cytoplasm contains an extensive endoplasmic reticulum. O. conifera swims at Reynolds numbers of 10 to 50, and is normally associated with surfaces (e.g. marine snow). We suggest that the unique anatomical and physiological characteristics of the luminescent system are related to the specialised ecological niche occupied by this species. Flashing is interpreted as a defensive response to potential predators
\end{abstract}

\section{INTRODUCTION}

Bioluminescence is a common attribute in the crustacean order Copepoda, occurring in at least 7 families (Herring 1988). It is found in most, if not all, species of the calanoid families Metridinidae, Lucicutidae, Heterorhabdidae and Augaptilidae. Oncaea conifera Giesbrecht (family Oncaeidae) is, however, the only poecilostomatoid species known to be luminescent. The luminescence of this species was first reported by Giesbrecht (1895) in specimens from the Gulf of Naples (Italy). He noted that the females had at least 70 luminous glands of variable shape and that those of the smaller males were similar but fewer in number.

The luminescence of calanoid copepods is visibly secretory in nature and is dispersed into the water by the movements of the animal (Bowlby \& Case 1991a, Widder 1992, Widder \& Herring unpubl.). The glands are usually large and the secretory material is vesicular or granular in nature (Bannister \& Herring 1990, Bowlby \& Case 1991b). Giesbrecht (1895), however, noted that those of Oncaea conifera were different.
Bioluminescence is not secretory but is confined within the glands (Herring 1988)

This investigation was undertaken to clarify the characteristics of the luminescence of Oncaea conifera and to compare these with the luminescent systems of other copepods. O. conifera is a widespread and abundant species in the world oceans, albeit in a variety of morphological forms (Moulton 1973, Malt 1983a). It is found at epi-meso- and bathypelagic depths (Malt 1983b) and may contribute a significant proportion of the potential luminescence of the zooplankton community.

\section{MATERIALS AND METHODS}

Copepods were obtained mainly from the eastern North Atlantic, on cruises of RRS 'Discovery' between 1981 and 1990, using a rectangular midwater trawl with a $1 \mathrm{~m}^{2}$ mouth area (RMT1) and a mesh of $330 \mu \mathrm{m}$ (Roe \& Shale 1979). Additional specimens were obtained from the Santa Barbara Channel and Monterey 
Bay (Pacific Ocean) in 1989. Specimens for quantum emission measurements were collected in the Alboran Sea (western Mediterranean Sea) in April 1991 and in the eastern North Atlantic in May 1991, using 0.5 or $0.75 \mathrm{~m}$ diameter conical nets towed for $15 \mathrm{~min}$ at approximately $0.5 \mathrm{~m} \mathrm{~s}^{-1}$. Specimens were obtained from a depth of $30 \mathrm{~m}$ in April 1991 and 100 to $170 \mathrm{~m}$ in May 1991, and were individually sorted into vials of filtered seawater and dark acclimated at 13 or $8^{\circ} \mathrm{C}$, respectively, for 18 to $23 \mathrm{~h}$ prior to testing to allow recovery of bioluminescence reserves (Latz et al. 1990).

Video recording. Characterization of the bioluminescence requires information on the quantum yield and kinetics of individual flashes, the flash capabilities of individual copepods and the responses of individual glands. The latter information can only be obtained from videarecordings of flashing copepods; these allow the time course of the luminescence of individual glands to be followed.

Three systems (available at different times and places) were employed for recording bioluminescence or swimming patterns. One system, used at sea, was the Mixed Light Imaging System (MLIS) which uses strobed infra-red illumination with an exposure time of 13 to $33 \mu \mathrm{s}$ at a frequency of $60 \mathrm{~Hz}$ (Widder 1992). Earlier video microscopy recordings of bioluminescence were also made at sea with a Delnocta triple stage image-intensifier mounted on a Vickers M41 Photoplan microscope and coupled to a National Panasonic Newvicon videocamera. In the laboratory at Santa Barbara (California, USA), a Dage 66 ISIT videocamera mounted on a Zeiss IM35 inverted microscope was used. For the MLIS recordings the copepods were free-swimming in aquaria $(35 \times 15 \times 60 \mathrm{~mm})$. Video microscopy recordings were made with the specimen held in a drop of seawater on a microscope slide.

Video recordings of swimming pattern were analyzed with a Megavision 1024XM image-analysis system. Each video frame was separated into individual fields and missing interlace lines filled as a mathematical average of the lines above and below them. For each swimming track 96 consecutive fields were mathematically combined and thresholded, producing a cumulative image of 96 strobes at a frequency of $60 \mathrm{~Hz}$.

Electrical stimulation and recording. Copepods were placed between 2 platinum electrodes and stimulated electrically with a Grass square-wave stimulator. The luminous responses were either videorecorded as described above or detected with an EMI 6097S photomultiplier operated at $1200 \mathrm{~V}$ and an analogue recording made on an S. E. Laboratories ultraviolet oscillograph. Electrical stimulation provides a quantitatively repeatable and defined stimulus of short duration, allowing a clearer analysis of the flash parameters.
Quantum emission. Measurements of quantum emission and kinetics of mechanically stimulated flashes were made in a 6 in $(=152 \mathrm{~mm})$ diameter integrating sphere collector (Labsphere, Inc.) coupled to a 2 in (= $51 \mathrm{~mm})$ diameter Burle 8850 photon-counting photomultiplier tube (see Latz et al. 1990 for details). Because the integrating sphere is a $4 \pi$ collector it measures total flux. Flashes were elicited by motor stirring, using either brief $(<1$ s) pulses or a constant speed of $2000 \mathrm{rpm}$. Photomultiplier output was converted to square wave (TTL) pulses by an amplifier/ discriminator (Pacific Instruments, model AD6). Pulses were counted in $10 \mathrm{~ms}$ time bins by an EG \& G Ortec ACE multichannel scalar operating in an IBM compatible PC. Records were of $40 \mathrm{~s}$ duration and were stored on disk for later analysis. Quantum calibration was determined by using an NIST-referenced multispectral source (Optronic Laboratories, model 310) to measure the spectral responsivity of the system. Based on the emission spectrum of Oncaea conifera (see below) a responsivity value of ca $5.8 \times 10^{3}$ photons TTL pulse $^{-1}$ was calculated.

Flashes were analyzed for the following variables (Latz et al. 1990): rise time, maximum flux, E-folding time (time from maximum flux to 1/e of maximum; its reciprocal gives the rate of exponential decay), decay time (based on $97 \%$ decay), total duration, flash quantum emission, total stimulable luminescence (TSL) for all flashes specimen ${ }^{-1}$, proportion of TSL in a single flash, and total flashes specimen ${ }^{-1}$. Because these variables displayed a lognormal rather than a normal distribution, values represent the geometric means and error based on the antilogarithms of the confidence limits of the log-transformed data (Sokal \& Rolf 1981). Statistical significance is based on the $5 \%$ probability level.

Spectral emission and fluorescence. The emission spectra of mechanically stimulated specimens were obtained with an EG \& G Princeton Applied Research Model 1460 optical multichannel analyser (OMA) operated and calibrated as described by Widder et al. (1983).

Fluorescence observations on live copepods were made with a Vickers Photoplan microscope and long wavelength ultraviolet incident illumination, viewed through a GG40 + 2E barrier filter. Photographs were taken on Tri-X film. Fluorescence spectra were recorded with the same system coupled by a fibre optic to the spectral analysis system described by Herring (1983)

Microscopy. Specimens were fixed for light and electron microscopy in $2.5 \%$ glutaraldehyde in phosphate buffer $\mathrm{pH} 7.4$, postfixed in $1 \%$ osmium tetroxide, dehydrated in a graded ethanol series and taken into Taab Ltd Premix medium grade resin via propylene 
oxide. Light microscope sections were cut on a Huxley Ultratome and stained with $1 \%$ toluidine blue in $1 \%$ sodium tetraborate.

Thin sections for transmission electron microscopy were cut on an LKB Ultratome 3, stained with aqueous uranyl acetate and lead citrate (Reynolds 1963) and examined on a Philips EM 301 electron microscope.

\section{RESULTS}

\section{Observations}

The female specimens from the Pacific were all of the 'slender' form (= 'long' form of Moulton 1973), the Mediterranean ones all of the 'stocky' form [corresponding to Giesbrecht's (1895) material] and the Atlantic specimens included 'stocky', 'bumped' and 'minus' forms. Atlantic males were only of the 'stocky' form. No differences were observed in the luminescence of the different forms.

The luminous glands were present on the dorsal and lateral regions of the body and appeared most densely concentrated around the anterior edge of the cephalosome and on the posterior urosome, particularly the furcal segment. In video replays of the responses it was also possible to identify flashing from legs 3 or 4 of several specimens (including one male). Each gland was associated with a single pore, equivalent to the integumental pore noted by Malt (1983a) (Fig. 1).

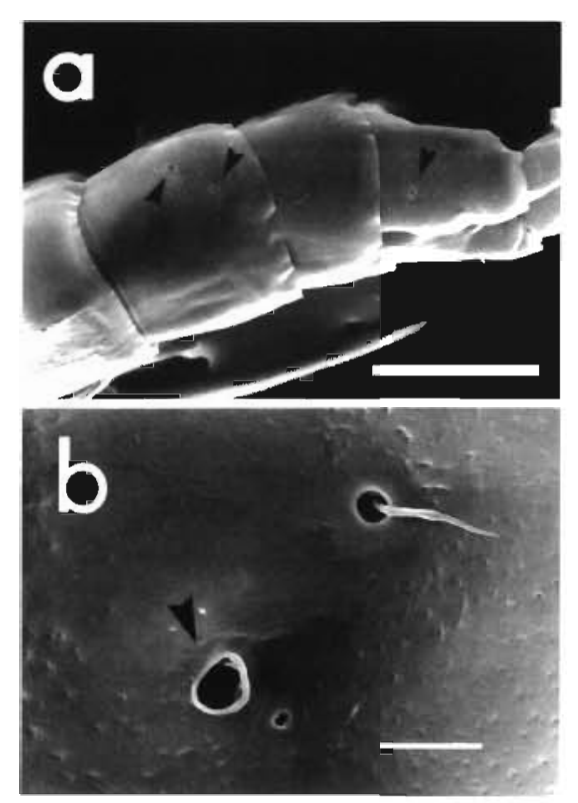

Fig. 1. Oncaea conifera. Scanning electron micrographs of luminescent gland pores (arrowheads) on (a) last 3 urosome segments and (b) cephalosome, of a copepod. A sensory pore, with a sensillum, is visible in (b) as well as a secondary pore associated with the main one. Scale bar $(a)=40 \mu \mathrm{m}$; (b) $=5 \mu \mathrm{m}$
The luminous glands could usually be readily identified by their blue-green fluorescence in long wavelength ultraviolet light (Fig. 2), except in the Pacific 'slender' forms in which there was little fluorescence. Non-fluorescent specimens were no less luminescent. In general the fluorescence intensity increased following stimulation and luminescence. The video recordings confirmed that the fluorescent cells were also the luminescent ones. Nevertheless their appearance in different individuals varied very greatly in number, form and position, although there was a basic segmental pattern to their arrangement (Fig. 2). At one extreme all the glands appeared as bulbous spots while at the other they had the form of elongate threads. Every gradation between the 2 could be found in different specimens and often the different glands in any one specimen showed similar variations. Even in elongate glands there was usually a bulbous region near the cuticular pore (Fig. 3).

Individual glands produce a short flash in response to a single electrical stimulus. Repeated stimuli at rates of 1 to $2 \mathrm{~s}^{-1}$ produce repeated flashes from each gland and this response can be very protracted, with the gland flashing at least 40 to 50 times over a period of 20 to $25 \mathrm{~s}$ of stimulation. In some specimens all the glands flash synchronously from the first stimulus (Fig. 4), but in others there is a gradual recruitment of glands during the initial period of stimulation. There is also potentiation within individual glands. The initial synchrony of all the glands tends to break down during repeated stimulation. Individual glands drop out of the regular response, only flashing ocasionally. Others no longer produce a short flash but rather a longer-lasting 'flare'. This results in varying flash decay kinetics in whole copepod responses (Fig. 5) Some glands become refractory for tens of stimuli before beginning to respond again. Individual glands were observed to follow a stimulus frequency of at least $5 \mathrm{~s}^{-1}$ for a limited period (we did not examine the effects of higher frequencies on single glands).

This description applies typically to glands that appear as small globular entities. Those that are visibly elongate or branching have an additional feature in their luminescence, in that single flashes propagate along their length. The flash first appears (and is brightest) at the broad vesicular section near the pore and travels down the ramifications of the gland. This is particularly clear in the urosome glands of both males and females. These are considerably longer than those of the cephalosome and the flash propagates anteriorly, sometimes throughout the entire length of the urosome. The start point for successive flashes may also move along the gland cell. The region where the flash first appears is where it persists longest, but this impression may be biased by the relative brightness and the time constant of the image intensifier. 

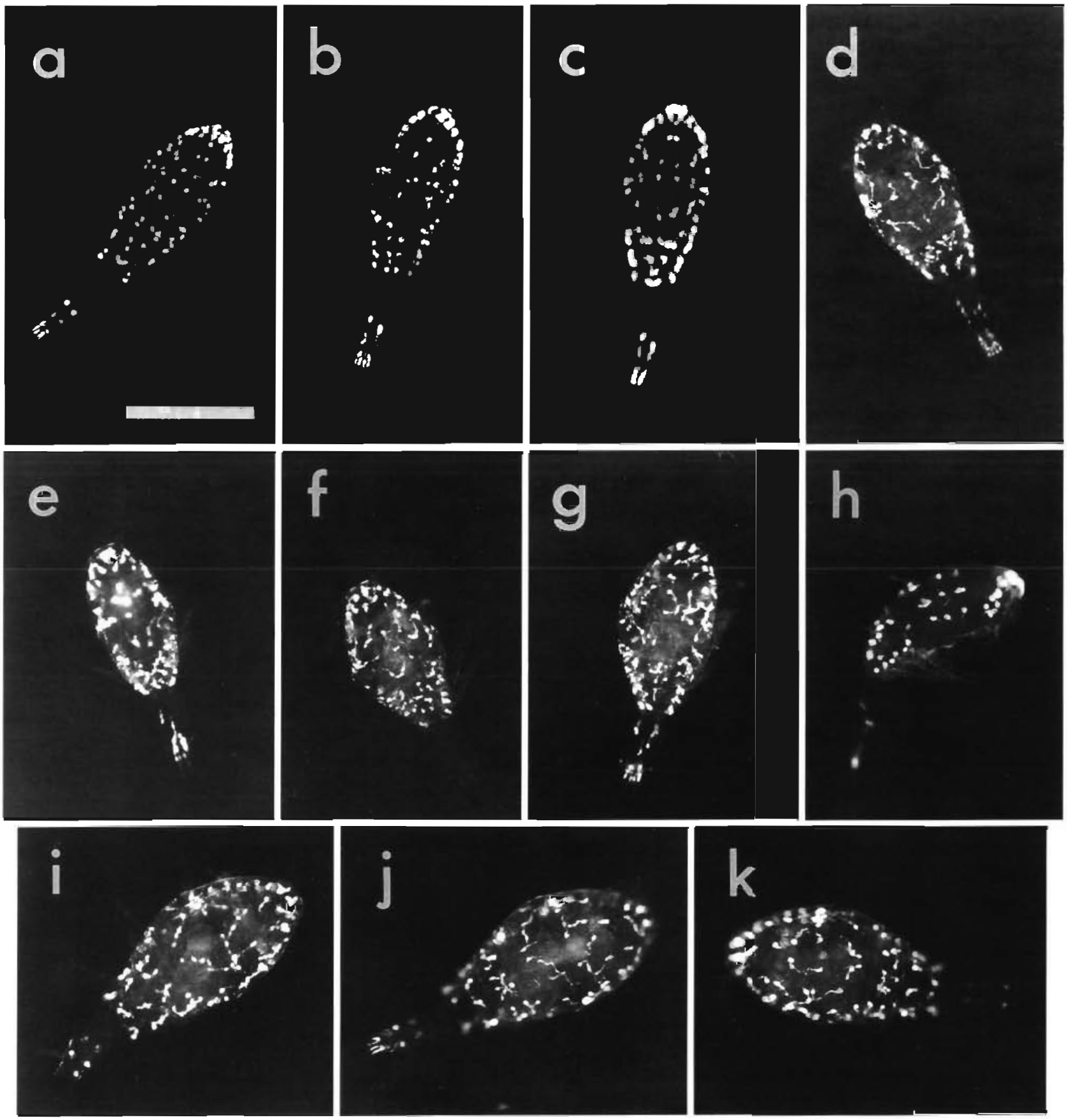

Fig. 2. Oncaea conifera. Morphological variability in the fluorescence patterns of live copepods. (a to d) Dorsal view of copepodites. (e to g) Dorsal viow of males. (h) Lateral view of copepodite. (i to k) Dorsal view of females. Scale bar $=0.5 \mathrm{~mm}$.

Males respond similarly in all respects and have similar variations in the appearance of their gland cells. The glands are probably slightly less numerous than in the females but are of similar distribution. Precopulatory paired males and females flash together when stimulated and there are no visible differences in their kinetics.

Some specimens flash 'spontaneously' when trapped on the microscope slide, often continuing randomly for periods of tens of seconds. Sometimes a single electrical stimulus results in a similar spontaneous discharge following the initial flash. In these animals the spontaneous flashes come from many different glands all apparently firing independently. Any one gland cell may, however, emit a brief series of flashes. If a spontaneously discharging animal is given a single supra-threshold electrical stimulus the spontaneous 

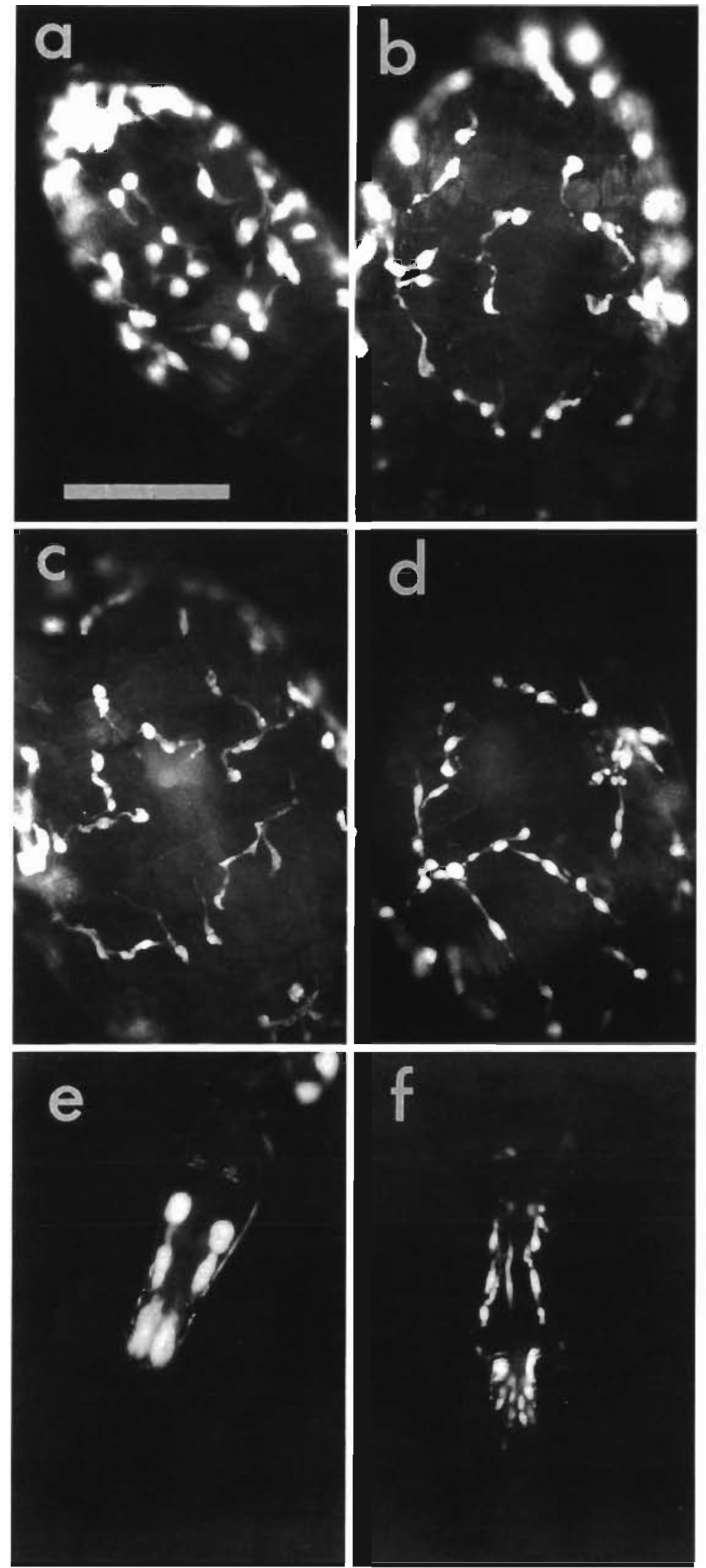

Fig. 3. Oncaea conifera. Detail of fluorescence patterns. (a) Copepodite cephalosome. ( $b$ to d) Adult female cephalosome. (e) Female urosome. (f) Male urosome. Scale bar $=0.2 \mathrm{~mm}$ discharge is briefly halted but recommences after a lag of several seconds

Similar random flashing (determined visually), albeit after a latency of tens of seconds, is induced by immersion in seawater containing $10^{-3} \mathrm{M}$ eserine, acetylcholine or carbamylcholine, but not by 5-hydroxy tryptamine (5HT, or serotonin), octopamine or adrenalin at the same concentration. Dose/ response analyses were not attempted. The eserine-induced flashes have very variable kinetics but include both typical fast, short flashes and longer glows (Fig. 6).

Luminous material was never seen to be secreted from the gland into the surrounding water.

\section{Flash kinetics and fluxes}

The measured flash kinetics and emissions of whole copepods represent the integrated responses of a large number of individual glands, as described above.

The average total mechanically stimulable luminescence (TMSL) per individual was $4.2 \times 10^{9}$ quanta (Table 1). Each specimen could produce a large number of flashes (Fig. 7) although the total number was extremely variable. May 1991 specimens averaged 41 flashes per specimen, but this understated the actual bioluminescence capacity because several specimens produced more than 100 flashes each, and 1 specimen produced 557 flashes without fully depleting its bioluminescence reserves. More typically each flash contributed some $1 \%$ of TMSL (Table 1 ).

Most flashes had fast kinetics and could be produced singly or in bursts; slow flashes were rarely observed (Fig. 8). Fast, mechanically stimulated flashes had mean rise times of 26 to $65 \mathrm{~ms}, 97 \%$ decay times of 59 to $144 \mathrm{~ms}$ and total durations of 89 to $214 \mathrm{~ms}$ (Table 1). Mean maximum intensity (flux) was $6.9 \times 10^{8}$ quanta $\mathrm{s}^{-1}$, with a highest measured value of $7.5 \times 10^{10}$ quanta $\mathrm{s}^{-1}$.

Fast flashes can be produced at a high repetition rate. On electrical stimulation there is a one-to-one relationship between flashes and electrical pulses. The flash responses of whole copepods follow the frequency of stimulation up to at least $30 \mathrm{~s}^{-1}$ (Fig. 9). Latencies to electrical stimuli were 


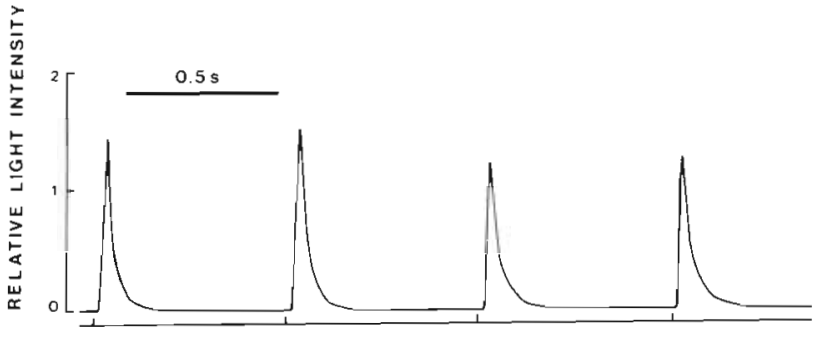

Fig. 4. Oncaea conifera. Luminescent responses to electrical stimuli. Synchronous flashing of all glands to $40 \mathrm{~V}$ stimuli of 10 ms duration (indicated by tick marks on the abscissa)

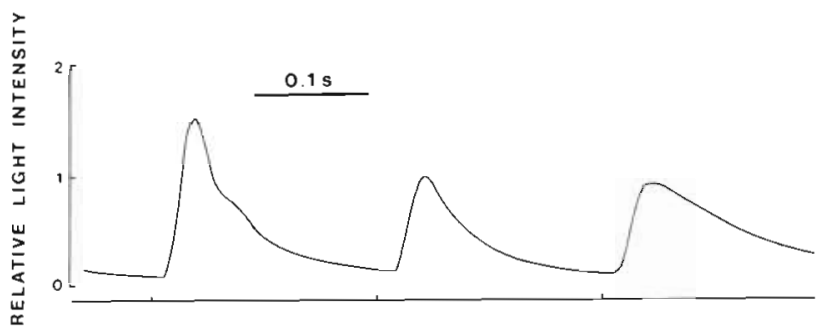

Fig. 5. Oncaea conifera. Differing flash decay kinetics of 3 consecutive flashes $(10 \mathrm{~ms}, 20 \mathrm{~V})$. The differences represent the integrated kinetics of many different glands

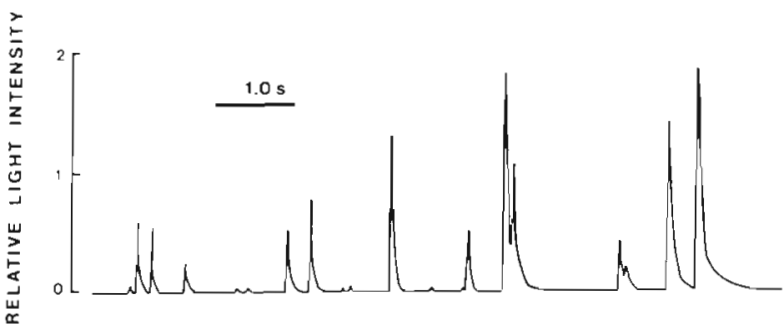

Fig. 6. Oncaea conifera. Chemical stimulation of bioluminescence. Copepod was immersed in seawater containing $10^{-3} \mathrm{M}$ eserine sulphate

5 to $20 \mathrm{~ms}$ and there was no evidence of a reduction in the latency to successive stimuli. The rise times of 30 to $70 \mathrm{~ms}, 90 \%$ decay times of 80 to $150 \mathrm{~ms}$ and total durations of 100 to $200 \mathrm{~ms}$ were very similar to those of mechanically induced flashes. During mechanical stimulation flashes were produced at the equivalent rate of approximately $4 \mathrm{~s}^{-1}$; maximum flash rate was $14 \mathrm{~s}^{-1}$ (Fig. 10).

The specimens from $60^{\circ} \mathrm{N}$ had longer flash kinetics than those from the Mediterranean. There were no differences in mechanically stimulated TMSL, maximum quantum flux, or total emission flash ${ }^{-1}$ (Table 1).

Atypical responses, including slow flashes and afterdischarges, were observed in both mechanically and electrically stimulated specimens, as well as in the video recordings (Fig. 11)

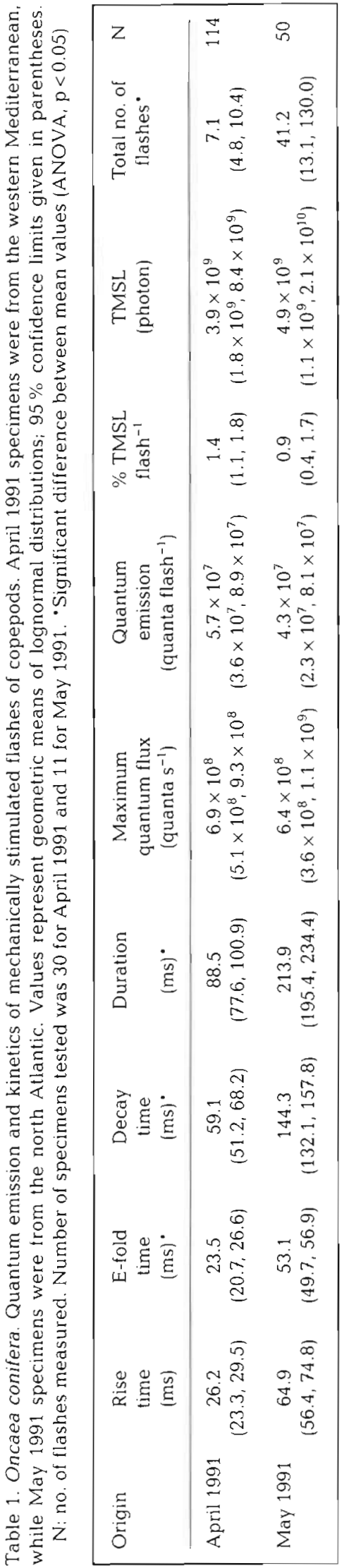




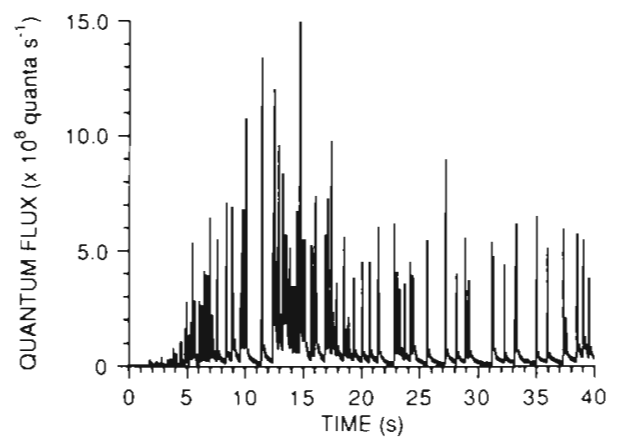

Fig. 7. Oncaea conifera. Response of 1 specimen to maintained mechanical stimulation. In this record approximately 77 flashes were produced in the $40 \mathrm{~s}$ period

\section{Spectral distribution}

The spectral distributions of the flashes of Pacific specimens had a $\lambda_{\max }$ at $469 \mathrm{~nm}$ and a full bandwidth at half maximum (FWHM) of $90 \mathrm{~nm}$. This is a substantially shorter wavelength emission that that of the calanoid copepods Metridia pacifica and Lucicutia flavicornis measured at the same time, which had $\lambda_{\max }$ of $489 \mathrm{~nm}$ and $483 \mathrm{~nm}$ respectively, both with FWHMs of $79 \mathrm{~nm}$ (Fig. 12).

Mediterranean specimens had an almost identical bioluminescence emission spectrum.

\section{Morphology}

Although the individual glands are invariably associated with a pore, they are not the only gland cells at each pore. Sections through the pore region show 2 cell types, a single fluorescent/luminescent cell and 1 or 2 non-fluorescent cells. The latter contain large vesicles and are usually globular in shape (Fig. 13a, b, c).

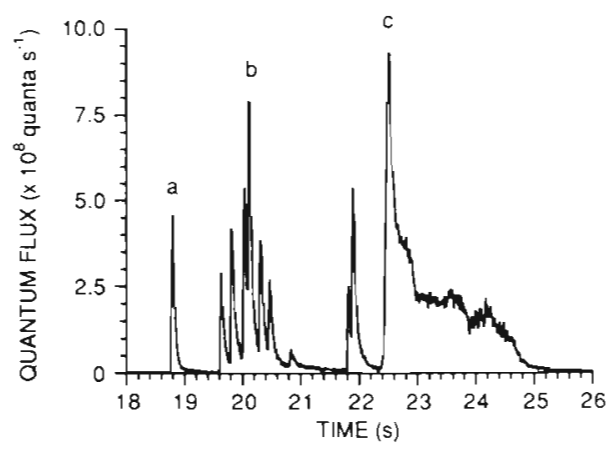

Fig. 8. Oncaea conifera. Variability of flash responses to mechanical stimulation. Part of the record from 1 specimen Fast flashes can be produced (a) singly, and (b) in bursts, while (c) slow flashes have a long decay

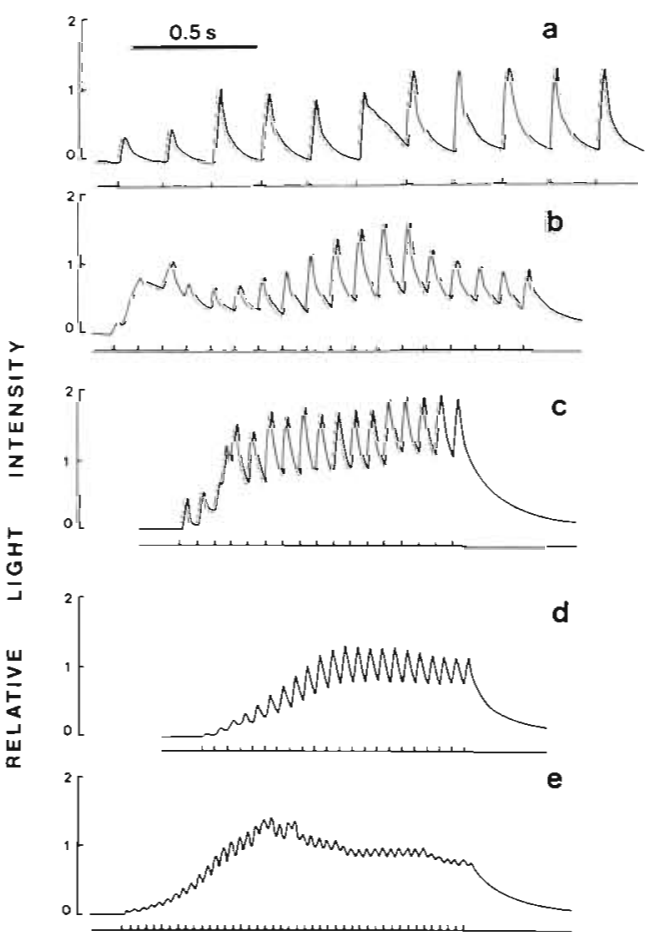

Fig. 9. Oncaea conifera. Bioluminescent responses to repetitive electrical stimuli. Responses are from the same individual to stimuli ( $1 \mathrm{~ms}, 20 \mathrm{~V})$ at frequencies of (a) 5 , (b) 10, (c) 15 , (d) 20 and (e) $30 \mathrm{~Hz}$

Sections of the luminescent cells often show both the 'tail' region and the typical bulbous region adjacent to the pore (Fig. 13c). The nucleus is usually associated with this bulbous region, which also contains an extensive network of rough endoplasmic reticulum (Fig. $13 g, h, i)$. The tail region is similar in general appearance except that the endoplasmic reticulum is a less dominant component. Where the cell approaches the pore, vesicular elements are sometimes visible

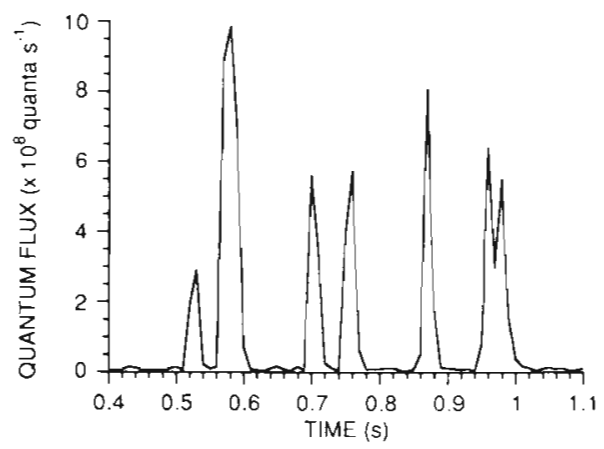

Fig. 10. Oncaea conifera. Flash burst in response to mechanical stimulation. In this record 7 flashes were produced during a $500 \mathrm{~ms}$ period, equivalent to 14 flashes $\mathrm{s}^{-1}$. Each fast flash had a duration of approximately $40 \mathrm{~ms}$ 


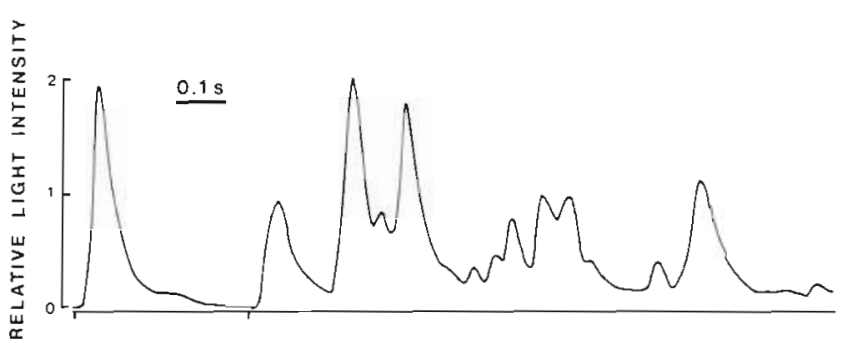

Fig. 11. Oncaea conifera. Complex luminous after-discharge following electrical stimuli $(10 \mathrm{~ms}, 30 \mathrm{~V})$. The record reflects independent and asynchronous flashing in different gland cells

(Fig. 13d, e, f). The pore itself has a valve-like flap just inside its external opening (Fig. 13e). In surface view the pore has no significant external architecture and is not associated with a sensillum (Fig. 1).

\section{Swimming patterns}

The video recordings of free-swimming specimens demonstrate the essentially jerky nature of their progress through the water, consequent upon the rapid deceleration following each power stroke. Measured mean speeds varied from 0.8 to $5.8 \mathrm{~cm} \mathrm{~s}^{-1}$ and trajectories were equally variable. The initial acceleration in a rapid burst of swimming reaches at least $75 \mathrm{~cm} \mathrm{~s}^{-2}$ (Fig. 14). Taking a body length of $1 \mathrm{~mm}$, a speed of 1 to $5 \mathrm{~cm} \mathrm{~s}^{-1}$, and a kinematic viscosity for seawater (at $20^{\circ} \mathrm{C}$ ) of $1.047 \times 10^{-6} \mathrm{~m}^{2} \mathrm{~s}^{-1}$, the Reynolds number (length $\times$ velocity/kinematic viscosity) for a swimming Oncaea conifera was calculated to be between 10 and 48. This is considerably lower than the $\mathrm{Re}$ of 300 suggested for a more typical copepod swimming at $20 \mathrm{~cm} \mathrm{~s}^{-1}$ (Vogel 1981).

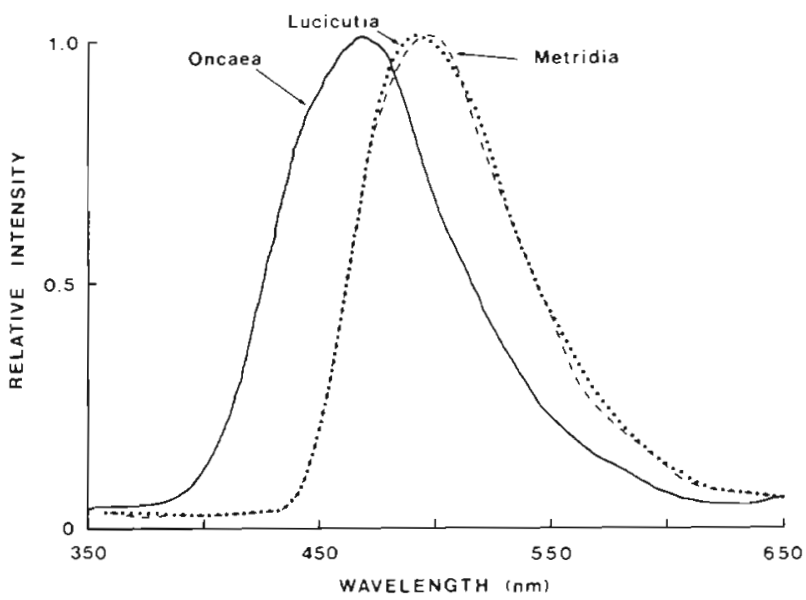

Fig. 12. Bioluminescence emission spectrum of Oncaea conifera (-), compared with those of Metridia pacifica (...) and Lucicutia flavicornis (...)

\section{DISCUSSION}

The bioluminescence of Oncaea conifera is very different from that of any other copepod. Despite the fact that it is the smallest of all luminous copepods (1 $\mathrm{mm})$ $O$. conifera probably has more luminous glands than any other species, including even the $10 \mathrm{~mm}$ long metridinid Gaussia princeps. It does share with the Metridinidae the fact that almost all its luminous sources are on the body rather than the legs, but there the comparison ends. The great difference from all other copepods is that the luminescence does not appear as an external secretion (Herring 1988). Nevertheless each bioluminescent gland cell is still closely associated with a simple tegumentary pore.

Pores are very widely distributed over the surface of all copepods and of many other Crustacea, whether luminous or not (Mauchline \& Nemoto 1977, Mauchline 1988). Their superficial appearance varies very little between species. Many of the described pores are sensory rather than secretory, but the usual process of preparation of the cuticle for pore identification destroys any sensillum and makes it difficult to distinguish between the different categories of pore. The simple pores with which the luminous cells of Oncaea conifera are associated have no particular distinguishing characteristics but are very small (only 1 to $2 \mu \mathrm{m}$ in diameter). They are the 'simplest type' described by Malt (1.983a). The valve-like structure visible in sections is too deeply sited to be visible from the exterior, unlike the valves in the larger apertures (up to $40 \mu \mathrm{m}$ ) of the luminous glands of the Metridinidae and Augaptilidae (Bannister \& Herring 1990, Bowlby \& Case $1991 \mathrm{~b}$ ). The valve appearance is similar to that in the pores of the non-luminous copepods Temora longicornis (Bannister 1993). Hemidiaptomus ingens (Brunet et al. 1991) and Tigriopus brevicornis (Gharagozlou-Van Ginneken 1979). This pore morphology appears to be a more general crustacean solution to the basic problems of glandular secretion, even though the secretions may have widely different functions

Three different types of glandular pore have been described in the non-luminous copepod Euchirella messinensis (Von Vaupel Klein 1982) but the functions of the underlying glands remain obscure. In Oncaea conifera there is often another morphological type of gland cell associated with the pore of the luminous gland. This gland is presumed to discharge via the same pore but its function is unknown. There is nothing to indicate that it has any connection with bioluminescence nor indeed is it known whether the cell type is present at every pore.

The fine structure of the luminous cells is quite unlike that of other copepod luminescent cells (Bannister 


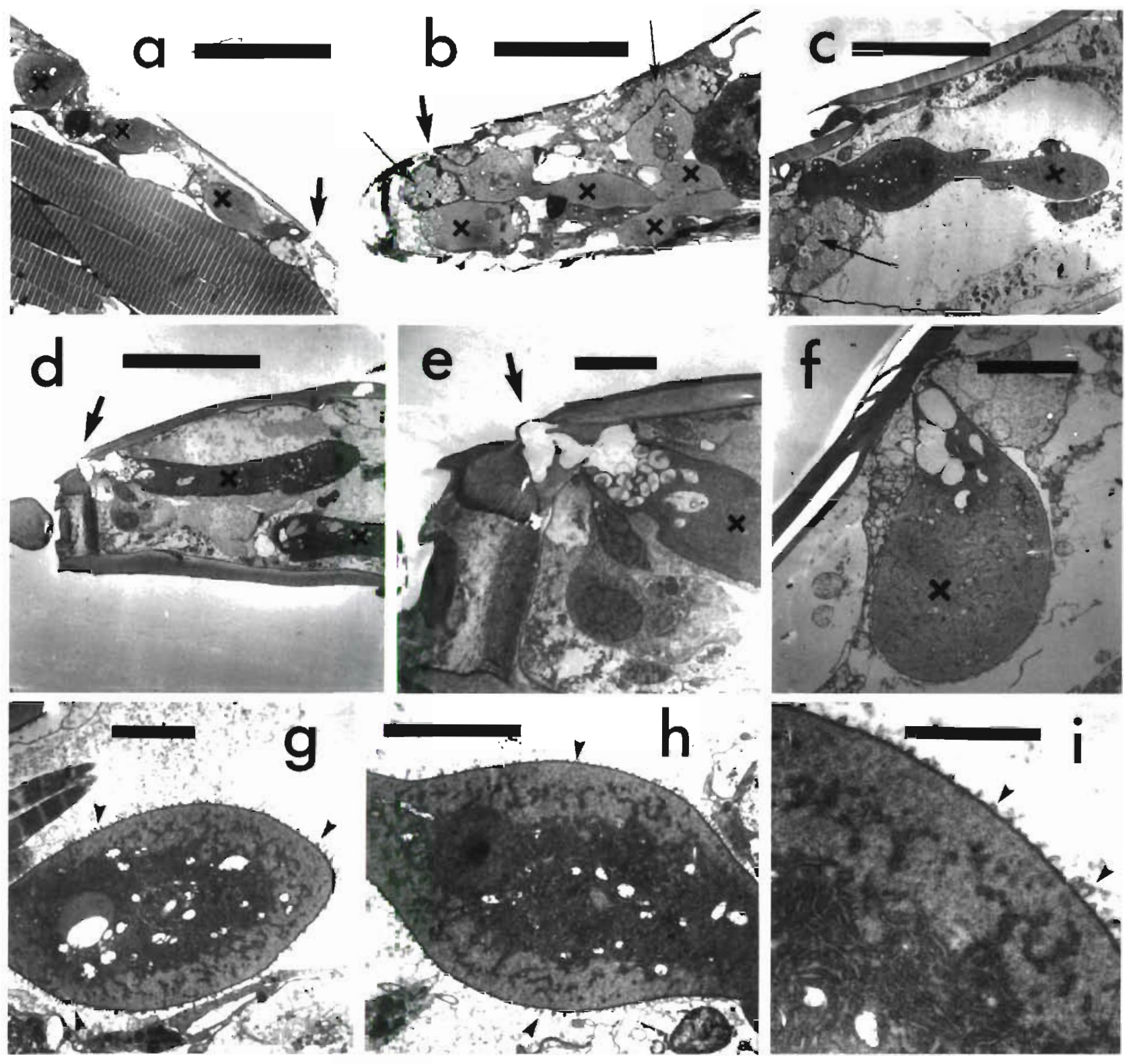

Fig. 13. Oncaea conifera. Morphology of luminous glands. $\mathbf{x}$ : luminous gland cell. (a) Sagittal section of glands on the cephalosome above the dorsal musculature. The 3 luminous gland cells are marked, and a pore is indicated by the arrow. (b) Sagittal section of the urosome, showing 4 luminaus gland cells. In the uppermost 2 the bulbous region and the tail are distinguishable. A second type of gland cell (small arrows) is associated with the pores of these 2 cells. (c) Electron micrograph of a sagittal section of a gland in the urosome. The nucleus is vis ble in the bulbous region and branching is demonstrated by the cytoplasmic stub. The arrow indicates the associated seconc type of gland cell. $(d$, e) Sagittal section of a gland cell in the urosome. The cytoplasm has a vesiculate appearance where it approaches the valve and pore. (f) Similar vesiculate appearance in a gland cell from the dorsal cephalosome. $(g, h, i)$ Electron micrographs of gland cells sectioned through the bulbous region, showing the extensive rough endoplasmic reticulum in the central core of this part of the cell. The plasma membrane is associated with small vesicular profiles (arrowheads). Scale bar (a,b) $=50 \mu \mathrm{m} ;(\mathrm{c}, \mathrm{d})=20 \mu \mathrm{m} ;(\mathrm{e}, \mathrm{f}, \mathrm{g}, \mathrm{h})=5 \mu \mathrm{m}$; (i) $=2 \mu \mathrm{m}$

\& Herring 1990, Bowlby \& Case 1991b) which always contain a secretory product in the form of vesicles or granules. The main feature of the cells of Oncaea conifera is an extensive network of rough endoplasmic reticulum within a cytoplasmic matrix. There is no defined secretory product, apart from the vesicles sometimes present adjacent to the pore. Associated with this is the fact that flashing is observed within the cells. This is much more akin to membrane-linked luminescence than to secretory luminescence. Propagation within the cells is not a phenomenon associated with secretion, nor is the very rapid kinetics of a typical 
A

B
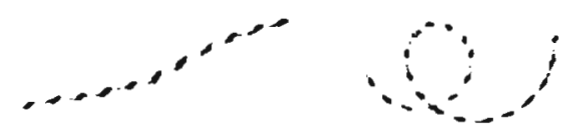

C

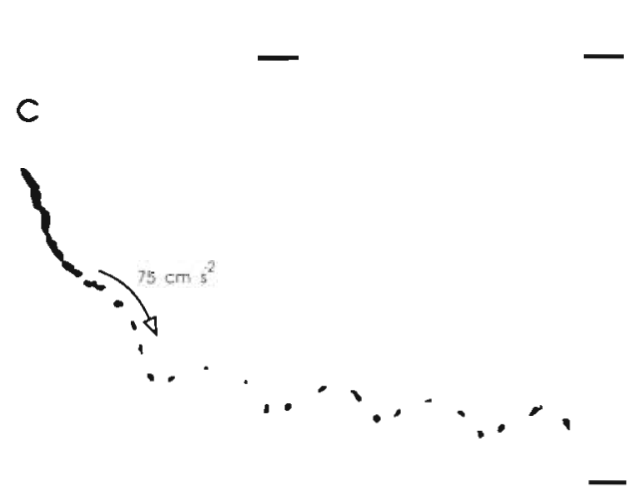

Fig. 14. Oncaea conifera. Swimming tracks of copepods. Normal jerky swimming pattern with a power stroke frequency of (A) $6 \mathrm{~Hz}$ and (B) $14 \mathrm{~Hz}$. Each track was produced from 96 infra-red strobed exposures at $60 \mathrm{~Hz}$. In both (A) and (B) swimming direction is from right to left and average swimming speed is 0.8 and $1.4 \mathrm{~cm} \mathrm{~s}^{-1}$ respectively. In (C), where swimming direction is from left to right, a rapid swimming bout is initiated with an acceleration of $75 \mathrm{~cm} \mathrm{~s}^{-1}$ over the distance indicated by the arrow. Swimming speed then oscillates between 5.8 and $3.9 \mathrm{~cm} \mathrm{~s}^{-1}$ with the faster velocity seen during the upward directed portion of the zig-zag swimming track. Scale bars $=2 \mathrm{~mm}$

Oncaea flash. The longer 'flares' or glows that have been observed probably reflect failure of the normal control processes.

There seems no obvious reason why the luminous cells should be associated with a pore at all. One possibility is that some product of the light-generating system needs to be excreted from the cell, and that this is achieved through the pore, perhaps in the form of the adjacent vesicles. An alternative hypothesis is that the ability to luminesce has evolved within cuticular glands whose original function was quite different. This has the attraction that it is not inconsistent with the isolated appearance of luminescence in Oncaea conifera, but nevertheless begs the question of why it remains isolated. As simple pores are present in other species of Oncaea (Malt 1983a), the implication is that they have associated gland cells, but we do not know whether these are morphologically similar to either of the 2 types present in $O$. conifera. Maintenance of the original function of a gland cell need not be precluded by the subsequent development of a bioluminescent capability.

Coelenterazine has been identified as the biochemical basis for bioluminescence in some other copepods (Campbell \& Herring 1990). If this applies equally to
Oncaea conifera it will be most interesting to know whether other (non-luminous) species of Oncaea lack this compound or whether it is present throughout the genus and $O$. conifera is the only species to have developed the requisite luciferase. The genus provides an appropriate model system for analysis of the evolution of the sporadic taronomic distribution of bioluminescence. This has continued to pose problems of interpretation since its earliest recognition (Harvey 1952).

The spectral distribution of the bioluminescence of other copepods shows some variability but generally has an emission maximum in the range 480 to $500 \mathrm{~nm}$. The spectrum is usually unimodal but sometimes has a shoulder at about 470 to $475 \mathrm{~nm}$ (Herring 1983, Widder et al. 1983, Latz et al. 1987, 1988). Giesbrecht (1895) reported that the colour of Oncaea conifera luminescence was visually bluer than that of other copepods, and spectral measurements confirm the shorter wavelength emission maximum. Two previous measurements, made on frozen and thawed material and with low signal to noise ratios, indicated a $\lambda_{\max }$ at even shorter wavelengths (ca $435 \mathrm{~nm}$ ) (Herring 1983). This discrepancy cannot be explained unless the process of freezing and thawing affects the spectrum. There is a slight inflexion at about $440 \mathrm{~nm}$ in the spectra reported here but its relevance is not clear. If an energy transfer process is involved, from a potentially shorter wavelength emission to the observed $469 \mathrm{~nm}$, a fluorescent compound of similar spectral characteristics would have been anticipated in the luminous cells. The fluorescence which is present has a corrected emission maximum at longer wavelengths (and a broader bandwidth) than the bioluminescence, and it increases in intensity after bioluminescence. It cannot therefore be a candidate for an energy transfer process.

The physiological features of the bioluminescence differ from those of other copepods. The main differences lie in the shorter flash duration and decay time and the multiplicity of the response compared with those of e.g. Pleuromamma xiphias (Latz et al. 1987. 1990). P. xiphias has 2 flash components, an initial fast component (which appears to be intracellular) and a subsequent slower component, attributable to externally secreted luminescent material (Latz et al. 1987). The kinetics of the fast component are similar to those of the whole Oncaea conifera flash, for in this copepod the intracellular component is the only one.

The intracellular mode of luminescence in Oncaea conifera is specialized for the production of repetitive fast flashes. A copepod can produce hundreds of flashes on mechanical stimulation, at rates of up to 14 flashes $s^{-1}$, although the physiological limit (based on electrical stimulation) is in excess of $30 \mathrm{~s}^{-1}$. The flashes are some of the fastest of any luminescent 
animal, averaging some 100 to $200 \mathrm{~ms}$ in duration, with some as short as $40 \mathrm{~ms}$. These are similar to those of small dinoflagellates, such as Gonyaulax spp. and Ceratium spp. (Krasnow et al. 1980, Lapota \& Losee 1984). Calanoid copepods have flash durations at least twice that of $O$. conifera (Barnes \& Case 1972, Latz et al. 1987, 1990, Bowlby \& Case 1991a, Latz unpubl.).

Flashing is under nervous control and the pharmacological evidence (based on eserine stimulation) suggests a cholinergic pathway. This is similar to the results for the amphipod genus Scina (Herring 1981) but differs from the luminescent systems of euphausiids and some decapod shrimps which are under serotonergic control (Herring 1976, Herring \& Locket 1978, Latz \& Case 1992).

The reasons for some of the differences in bioluminescent physiology between Oncaea conifera and other copepods may be a function of size. Video analysis of the luminous responses of larger copepods has shown that they are unable to eject the luminescent material beyond the boundary layer without additional swimming movements. These either generate water currents which flush the material away from the gland aperture or, in vigorous escape responses, effectively throw it off the surface of the animal (Bowlby \& Case 1991a, Widder 1992, Widder \& Herring unpubl.). An animal the size and shape of $O$. conifera cannot travel more than a few body lengths with each power stroke and progresses in a series of short jerks. It is heavily constrained by the viscous and inertial forces of the water in which it moves; it swims at a Reynolds number of about 50. It is therefore virtually impossible for it to escape rapidly from any material entrained in its own boundary layer, as a glandular secretion would be. Throwing off bioluminescence as a decoy defense, as other copepods do, is therefore not a practicable option. The value of its bioluminescence is thus as flashes whose brevity, intensity and potential repetition may serve to deter a predator. In this respect it perhaps has parallels with the flashes of dinoflagellates or many cnidarians which disrupt predator feeding activity (Esaias \& Curl 1972, Buskey et al. 1985). The small pore diameter will limit the potential flow rate of the material to the exterior. If the pore/gland cell complex was originally evolved for some other purpose (e.g. gradual secretion of pheromones or of excretory, hydrodynamic or anti-fouling materials) its dimensions may have constrained the way in which it can be adapted to other purposes. Other small species (and developmental stages) of luminous copepods may face similar difficulties. Pleuromamma gracilis and some Lucicutia species are only slightly larger (1 to $2 \mathrm{~mm}$ ) but both are capable of a gliding swimming motion and a rapid escape jump, unlike Oncaea. The harpacticoid copepod Aegisthus mucronatus is also luminescent and has a rather similar style of locomotion to $O$. conifera. Nevertheless first observations suggest that its luminescence is not intracellular but secretory, with equivalent kinetics

Specimens of Oncaea media, O. mediterranea, $O$. venusta and $O$. ornata were all tested for bioluminescence but without success. It seems likely that $O$. conifera is unique within the genus, but this cannot be unequivocally determined until specimens of the other species which also have the dorsal projection (O. antarctica, $O$. borealis, $O$. clevei and $O$. inflexa) are examined. Nothing is known of any ecological differences between the species which might explain the adaptive significance of bioluminescence in the one species but not in the others.

Oncaea conifera is probably not routinely freeswimming. The Oncaeidae are included within the recently-defined order Poecilostomatoida (Huys \& Boxshall 1991), almost all of which are parasites or associates of other animals. The pelagic Oncaeidae and Sapphirinidae tend to be associated with salps, mucoid aggregates (marine snow) and larvacean houses (Sewell 1947, Alldredge 1972, Heron 1973). Despite its presence in the pelagic environment, $O$. conifera is associated with surfaces; its habitat is therefore more akin to an epibenthic one. This may have determined its locomotory pattern and, in turn, its unique bioluminescent responses.

Oncaea conifera is present in large numbers in mesopelagic samples in the north Atlantic. Indeed it was the numerically dominant luminous copepod at nightime depths of 300 to $800 \mathrm{~m}$ at $60^{\circ} \mathrm{N}, 20^{\circ} \mathrm{W}$ and 200 to $500 \mathrm{~m}$ at $53^{\circ} \mathrm{N}, 20^{\circ} \mathrm{W}$ (Table 2). It has not been included in published bioluminescence budgets (e.g. Batchelder \& Swift 1989) but even though its TMSL is an order of magnitude less that that of some calanoid

Table 2. Oncaea conifera as a proportion of the total number of luminous copepods taken at nightime at $60^{\circ} \mathrm{N}, 20^{\circ} \mathrm{W}$ and $53^{\circ} \mathrm{N}, 20^{\circ} \mathrm{W}$ in 1971 . The net used was an RMT 1 with a $1 \mathrm{~m}^{2}$ mouth area and a mesh of $330 \mu \mathrm{m}$. All Oncaea with a dorsal hump were assumed to be $O$. conifera; other luminous copepods were identified only to genus. ND: no data

\begin{tabular}{|ccc|}
$\begin{array}{c}\text { Depth horizon } \\
(\mathrm{m})\end{array}$ & $\begin{array}{c}60^{\circ} \mathrm{N}, 20^{\circ} \mathrm{W} \\
(\%)\end{array}$ & $\begin{array}{c}53^{\circ} \mathrm{N}, 20^{\circ} \mathrm{W} \\
(\%)\end{array}$ \\
\hline $0-100$ & 1 & 6 \\
$100-200$ & 0 & $\mathrm{ND}$ \\
$200-300$ & 2 & 41 \\
$300-400$ & 71 & 57 \\
$400-500$ & 78 & 44 \\
$500-600$ & 61 & 40 \\
$600-700$ & 69 & 31 \\
$700-800$ & 53 & 16 \\
$800-900$ & 16 & 12 \\
$900-1000$ & 9 & 5 \\
\hline
\end{tabular}


copepods (Batchelder \& Swift 1989, Latz et al. 1990) its abundance may indicate a significant contribution to bioluminescence potential (and hence the visual ecology) at these depths.

Acknowledgements. We are most grateful to Dr G. Boxshall for the identification of many of the specimens and to $S$. Haddock for providing spectral data from the Mediterranean specimens. Prof. J. F. Case generously provided laboratory facilities and support for one of us (P.J.H.) at Santa Barbara. We thank the captains and crews of RRS 'Discovery', RV 'Edwin Link', and RV 'Endeavor' for their assistance at sea. N.J.B.'s contribution is based upon graduate student work at UCNW, Bangor, during a NERC/ CASE studentship. Harbor Branch Oceanographic Institution Contribution no. 952.

\section{LITERATURE CITED}

Alldredge, A. L. (1972). Abandoned larvacean houses: a unique food source in the pelagic environment. Science 177: $885-887$

Bannister, N. J. (1993). Distribution and structure of the sub-cuticular glands in the copepod Temora longicornis. J. mar. biol. Ass. U.K. 73: 97-107

Bannister, N. J., Herring, P.J. (1990). Distribution and structure of the luminous cells in four marine copepods. J. mar. biol. Ass. U.K. 69: 523-533

Barnes, A. T., Case, J. F. (1972). Bioluminescence in the mesopelagic copepod, Gaussia princeps (T. Scott). J. exp. mar. Biol. Ecol. 8: 53-71

Batchelder, H. P., Swift, E. (1989). Estimated near-surface mesoplanktonic bioluminescence in the Western North Atlantic during July 1986. Limnol. Oceanogr. 34: 113-128

Bowlby, M. R., Case, J. F. (1991a). Flash kinetics and spatial patterns of bioluminescence in the copepod Gaussia princeps. Mar. Biol. 110:329-336

Bowlby, M. R., Case, J. F. (1991b). Ultrastructure and neuronal control of luminous cells in the copepod Gaussia princeps. Biol. Bull. 180: 440-446

Brunet, M., Cuoc, C., Arnaud, J., Mazza, J. (1991). Tegumental glands in a copepod Hemidiaptomus ingens: structural, ultrastructural and cytochemical aspects. Tissue Cell 23: $733-743$

Buskey, E. J., Reynolds, G. T., Swift, E., Walton, A. J. (1985). Interactions between copepods and bioluminescent dinoflagellates: direct observations using image intensification. Biol. Bull. 169: 530

Campbell, A. K., Herring, P. J. (1990). Imidazolopyrazine bioluminescence in copepods and other marine organisms. Mar. Biol. 104: 219-225

Esaias, W. E., Curl, H. C. (1972). Effect of dinoflagellate bioluminescence on copepod ingestion rates. Limnol. Oceanogr. 17: 901-906

Gharagozlou-Van Ginneken, I. D. (1979). Etude ultrastructurale et cytochimique de l'activite temporaire des glandes tegumentaires d'un Crustace Copepode. Annls Sci. nat. Zool., Paris 1: 205-212

Giesbrecht, W. (1895). Mitteilungen über Copepoden. 8. Über das Leuchten der pelagischen Copepoden und das tierische Leuchten im Allgemeinen. Mit. zool. Stn Neapel 11. $648-689$

Harvey, E. N. (1952). Bioluminescence. Academic Press, New York
Heron, A. C. (1973). A specialized prey-predator relationship between the copepod Sapphirina angusta and the pelagic tunicate Thalia democratica. J mar. biol. Ass. U.K. 53: $429-435$

Herring, P. J (1976). Bioluminescence of decapod Crustacea. J. mar. biol. Ass. U.K. 56: 1029-1047

Herring. P. J. (1981). Studies on bioluminescent marine amphipods. J. mar. biol. Ass. U.K. 61: 161-176

Herring, P. J. (1983). The spectral characteristics of luminous marine organisms. Proc. R. Soc. Lond. B 220: 183-217

Herring, P. J. (1988). Copepod luminescence. Hydrobiologia 167/168: $183-195$

Herring, P. J., Locket, N. A. (1978). The luminescence and photophores of euphausiid crustaceans. J. Zool. Lond. 186: $431-462$

Huys, R., Boxshall, G. A. (1991). Copepod evolution. The Ray Society, London

Krasnow, R., Dunlap, J. C., Taylor, W., Hastings, J. W., Vetterling, W., Gooch, V (1980). Circadian spontaneous bioluminescent glow and flashing of Gonyaulax polyedra. J. comp. Physiol. 138: 19-26

Lapota, D., Losee, J. R. (1984). Observations of bioluminescence in marine plankton from the Sea of Cortez. J. exp. mar. Biol. Ecol. 77: 209-240

Latz, M. I., Bowlby, M. R., Case, J. F. (1990). Recovery and stimulation of copepod bioluminescence. J.exp mar. Biol. Ecol. 136: 1-22

Latz, M. I., Case, J F. (1992). Slow photic and chemical induction of bioluminescence in the midwater shrimp Sergestes similis Hansen. Biol. Bull. 182: 391-400

Latz, M. I., Frank, T. M., Bowlby, M. R., Widder, E. A., Case, J. F. (1987). Variability in flash characteristics of a bioluminescent copepod. Biol. Bull. 173: 489-503

Latz, M. I., Frank, T M., Case, J. F. (1988). Spectral composition of bioluminescence of epipelagic organisms from the Sargasso Sea. Mar. Biol. 98: 441-446

Malt, S. J. (1983a). Polymorphism and pore signature patterns in the copepod genus Oncaea (Cyclopoida). J. mar. biol. Ass. U.K. 63: $441-446$

Malt, S. J. (1983b). Copepoda, Oncaea, Fich. Ident. Zooplancton. Nos 169/170/171.

Mauchline, J. (1988). Taxonomic value of pore pattern in the integument of calanoid copepods (Crustacea). J. Zool. Lond 214: $697-749$

Mauchline, J., Nemoto, T (1977). The occurrence of integumental organs in copepodid stages of calanoid copepods. Bull. Plankton Soc. Jap. 24: 108-114

Moulton, T P. (1973). Principal component analysis of variation in form within Oncaea conifera (Giesbrecht, 1891), a species of copepod (Crustacea). Syst. Zool. 22: 141-156

Reynolds, E. S. (1963). On the use of lead citrate at high pH as an electron opaque stain in electron microscopy. J. Cell Biol. 17: 208-212

Roe, H. S. J., Shale, D. M. (1979). A new multiple rectangular midwater trawl (RMT $1+8 \mathrm{M}$ ) and some modifications to the Institute of Oceanographic Sciences' RMT 1+8. Mar. Biol. 50: 283-288

Sewell, R. B. S. (1947). The free-swimming planktonic Copepoda. Systematic account. Sci. Rep. John Murray Exped. 1933-34 (Zoology) 8: 317-592

Sokal, R. R., Rohlf, F. J (1981). Biometry. W. H. Freeman \& Co., New York

Vogel, S. (1981). Life in moving fluids. Princeton Univ. Press, Princeton

Von Vaupel Klein, J. C. (1982). Structure of integumental perforations in the Euchirella messinensis female (Crustacea, Copepoda, Calanoida). Neth. J. Zool. 32: 374-394 
Widder, E. A. (1992). Mixed light imaging system for recording bioluminescent behaviours. J. mar. biol. Ass. U.K. 72 : $131-138$

This article was submitted to the editor
Widder, E. A., Latz, M. I., Case, J. F. (1983). Marine bioluminescence spectra measured with an optical multichannel detection system. Biol. Bull. 165: 791-810

Manuscript first received: December 14, 1992 Revised version accepted: February 15, 1993 